\title{
ASSOCIAÇÃO ENTRE A INSATISFAÇÃO CORPORAL E SUA RELAÇÃO COM O CRESCIMENTO DE CIRURGIAS PLÁSTICAS ESTÉTICAS
}

\author{
Juliana Bezerra de Almeida ${ }^{1}$ \\ Allyne Evellyn Freitas Gomes ${ }^{2}$
}

RESUMO: Uma das grandes obsessões da atualidade é a adoração ao corpo belo e "perfeito", e esse fanatismo com a autoimagem corporal tem conduzido ao aumento pela procura por cirurgias plásticas estéticas entre os jovens adultos brasileiros. Essa inquietação com os padrões estéticos em níveis excessivos tem se mostrado preocupante, já que os mesmos desafiam os limites do seu próprio corpo e não conseguem distinguir determinadas ações que podem ser prejudiciais à saúde e à vida. Sendo assim, o presente estudo tem como finalidade compreender a associação entre a insatisfação corporal e a ditadura dos padrões de beleza, bem como sua relação com o crescimento de cirurgias plásticas estéticas nos últimos anos. A metodologia utilizada desse projeto será um levantamento bibliográfico acerca do tema por meio da revisão narrativa de artigos publicados nas bases de dados da Literatura Latino Americana e do Caribe em ciências de saúde (LILACS), Public/Medline ou Publisher Medline (PUBMED) e Scientific Eletronic Library online (SCIELO). Serão utilizados artigos publicados entre os anos de 2016-202I, nos idiomas português e inglês, utilizando para pesquisa os descritores de saúde (DeCS): cirurgia plástica; estética; imagem corporal; insatisfação corporal; padronização corporal. Diante dos dados coletados foi possível constatar que a busca por um corpo dentro dos considerados "padrões de beleza", tem gerado insatisfação corporal, o que pode influenciar na busca por procedimentos estéticos que possam culminar em prejuízos à saúde dos indivíduos, seja consequências nutricionais, psicossociais ou física a curto, médio e longo prazo.

Palavras-chave: Adulto jovem. Autoimagem. Cirurgia estética. Imagem corporal. Padronização corporal

\section{INTRODUÇÃO}

A imagem Corporal (IC) é a figura do próprio corpo que forma a mente, ou seja, o modo pelo qual o corpo se apresenta. ${ }^{1} \mathrm{~A}$ imagem corporal é construída ao longo da vida, por meio das transformações constantes e está interligada com as experiências adquiridas ao longo do percurso; quanto mais experiências adquiridas mais ampla será sua visão de imagem corporal ${ }^{5}$. A autoimagem pode ser entendida como a forma com que o ser humano

\footnotetext{
I Graduanda em Nutrição pelo Centro Universitário Maurício de Nassau - UNINASSAU.

${ }^{2}$ Mestre em psicologia-UFPE. Psicopedagoga, Psicanalista e psicóloga.
} 
se enxerga, como pensa que é ou como se vê. ${ }^{29}$ Evidenciando suas experiências anteriores, vivências e perspectivas presentes e futuras, considerando questões referentes a volume, fisionomia e emoções. 5 A autoestima pode influir na formação da autoimagem, visto que a maior obsessão da atualidade é a adoração ao corpo "belo e perfeito" 5 .

Dito isto, pode-se constatar que a imagem corporal é formada por três princípios: o físico, o psíquico e o sociológico. O primeiro é evidenciado pelas impressões visuais e táteis que o indivíduo tem sobre o seu corpo, o segundo relaciona-se às motivações inconscientes, e o terceiro princípio refere-se aos experimentos sociais que influem para a formação da imagem individual..$^{5}$ No entanto, acredita-se que esse padrão está em constante ascensão e descensão, pois o indivíduo está sempre ressignificando a sua imagem ${ }^{5}$.

O fanatismo com a autoimagem corporal tem aumentado nos últimos anos, e a palavra "beleza" obteve um sentido de acolhimento ou desacolhimento ${ }^{5}$. Essa inquietação com os padrões estéticos em níveis excessivos tem se mostrado preocupante, motivados pela cultura da "boa aparência" e das incontáveis publicações sobre o corpo ideal que na maioria das vezes estão interligadas ao sucesso profissional, volúpia e recognição social ${ }^{5}$. A adoração ao corpo "perfeito" se torna uma fixação tão comum que não se consegue distinguir determinadas ações prejudiciais à saúde. ${ }^{2}$ Segundo Alves (201I) ${ }^{3}$, "a procura pela beleza, em vez de ser um modo de elevar a autoestima, acabou virando um jeito de morrer mais jovem e rápido.

Sendo assim, várias regras e padrões foram exigidos pela sociedade, abrindo caminho à ditadura da beleza, e quem não a segue é julgado ou enxergado como esquisito. ${ }^{2}$ Alguns estudos científicos apontam que as pessoas que possuem peso eutrófico ou abaixo do peso mostraram pontos de insatisfação corporal elevados em comparação aos que estão em sobrepeso ${ }^{5}$, deste modo, a imagem corporal é passível de ser influenciada pela grandeza corporal, excluindo assim a junção com a idade e o sexo ${ }^{5}$.

A insatisfação corporal é uma ideia negativa que o indivíduo cria sobre o seu físico, ocasionando sentimento de desagrado e frustração sobre o seu corpo. ${ }^{5} \mathrm{O}$ número de pessoas com problemas de distorção de imagem tem aumentado constantemente, e alguns estudos mostraram que os universitários da área da saúde são mais propensos a desenvolverem Insatisfação com o corpo ${ }^{6}$ E o motivo pelo qual ocasionou esse aumento é justificado pelo 
conflito entre "a aparência física atual" e "a aparência física ideal" .5 Esse desagrado com a IC tem crescido graças a influência que a mídia detém e que tem conduzido diversas pessoas a procurarem submetidos os procedimentos estéticos e cirúrgicos ${ }^{5}$, apesar do perigo que são. ${ }^{4}$

Deste modo, a busca infindável pela transformação estética comprova o estímulo que a Dispersão dos protótipos estéticos e da procura desse "padrão adequado" ultrapassam as linhas de riscos que demarcam a vida e a morte. ${ }^{4}$

Diante dos dados coletados foi possível constatar um aumento expressivo na procura por cirurgias plásticas estéticas invasivas no país e que concomitantemente cresce o número de jovens mortos por causa desses procedimentos, o que nos faz refletir e se questionar acerca da ditadura da beleza e suas consequências sobre a saúde dos indivíduos e até que ponto o indivíduo é capaz de chegar pela estética? Sendo assim, o presente estudo teve como objetivo compreender a associação entre a insatisfação corporal e a ditadura dos padrões de beleza, bem como sua relação com o crescimento de cirurgias plásticas estéticas.

\section{METODOLOGIA}

A metodologia utilizada desse projeto será um levantamento bibliográfico acerca do tema por meio da revisão narrativa de artigos publicados nas bases de dados da Literatura Latino Americana e do Caribe em ciências de saúde (LILACS), Publisher Medline PUBMED) e Scientific Eletronic Library online (SCIELO). Serão realizadas também pesquisas em sites governamentais como: Organização Mundial da Saúde (OMS) e Diretrizes da Sociedade Brasileira de Cirurgias Plásticas. Foram utilizados os seguintes descritores de saúde (DeCS): cirurgia plástica; estética; imagem corporal; insatisfação corporal; padronização corporal.

Os critérios de inclusão para a seleção desses estudos foram : artigos de revisão e originais que abordassem a temática, publicados em outros idiomas, entre 2016 e 2021. Caso necessário, serão adicionados estudos de anos anteriores que apresentarem pertinência ao tema, como os clássicos da literatura, que estiverem indexados nas bases de dados supracitadas. Como critérios de exclusão estão: artigos originais não realizados com humanos, trabalhos que não apresentarem resumos na íntegra nas bases de dados e que não demonstrem caráter científico. 
Os artigos encontrados foram inicialmente analisados a partir dos títulos e resumos. Após a seleção serão lidos na íntegra para verificar a pertinência de inclusão dos mesmos no estudo. Somente após essas fases, foi realizada a extração de dados, bem como organização e síntese dos principais resultados.

\section{RESULTADOS E DISCUSSÃO}

\section{I. Corpo e mente: objeto de estudo na contemporaneidade}

Groddeck originou corpo e mente como um fato singular e inseparável ${ }^{16}$. Segundo René Descartes (1996) ${ }^{18}$, conceituou corpo e mente como duas coisas diferentes e que correspondem a dois hemisférios distintos: o hemisfério das coisas expandidas, objetos e o hemisfério das ideias ou dos elementos abstratos, mesmo sendo hemisfério distintos, corpo e mente andam lado a lado, quando um não funciona bem o outro também pode ser afetado. Seguindo essa racionalidade surgirá seguimento de especificação e singularizacao, além da distinção dos hemisférios: as patologias físicas e as patologias psíquicas ${ }^{18}$. E entre esses dois hemisférios permeia a psicossomática, sendo um campo enigmático ${ }^{18}$. É fato que o corpo

entrou em destaque e vem ganhando espaço na vida dos indivíduos na atualidade ${ }^{20}$. A adoração extrema pelo o corpo perfeito, a busca incessante em retardar a senescência em uma comunidade com valores invertidos, e irrelevante, veem causando uma acentuada modificação de conduta e hábitos da população ${ }^{12}$.Mas, será que devemos evidenciar e nos preocupar apenas com o corpo?Se corpo e mente são fatos singulares e inseparável porque não se preocupar com a mente também? ${ }^{16}$

Segundo Novaes (2006) 13, vivemos em um mundo onde os princípios ficam em segundo plano e o corpóreo em primeiro. O padrão de beleza imposto pela sociedade e pela mídia e a percepção corporal de si, fundamentam o aumento expressivo de pessoas insatisfeita com seu corpo ${ }^{13}$. A linguagem corporal trata das conexões internas à comunidade e também procura a satisfação e a alegria absoluta. ${ }^{17} \mathrm{Em}$ uma comunidade excessiva no reconhecimento do valor que aparência possui, difícil é o percurso de quem escolhe trilhar outros caminhos além da aparência ${ }^{20}$. A procura do indivíduo em se encaixar nos padrões estéticos, o faz esquecer sua genuinidade e naturalidade, o que patenteia o olhar da perspectiva fenomenológica existencial, o ter se sobressaindo sobre o ser, nesse caso, o ter seria saciado pela conquista ou alcance do corpo almejado. ${ }^{\text {Io }}$ 
Nesse sentido, analisamos a supervalorização do corpo na atualidade, os antagonismos alimentares e a edificação do olhar, ultrajante e humilhante sobre o outro ${ }^{14}$. A forma corpórea entra em ação e com a mesma surgiu várias maneiras de ludibriar a feiura, respaldado no princípio de aceitação á corpolatria encontra-se ligada a mecanismos de boa vivência ${ }^{15}$.

Todas as outras coisas aparentam constituir em meras ideias para atingir, aquilo que se constitui, na atualidade, a mesma coisa de redenção psíquica e social: "Estrutura física impecável" ${ }^{19}$.

\subsection{Conflitos na Autopercepção do eu}

Segundo Novaes (200I) ${ }^{12}$, "O corpo é o centro do cotidiano de cada pessoa, em suas aspirações de saúde perfeita, juventude eterna e beleza ideal". Além do mais, a estrutura física é o cenário de contradições e divergências, visto que a mesma estrutura corpórea que procura a peculiaridade abstém a distinção e a diversidade. O sujeito assimila apreciar face a face, nutrindo a aceitar o eu como um produto viável para aquisição ${ }^{14}$. $\mathrm{O}$ indivíduo é responsável pela sua imagem corporal, culpabilizando a si mesmo quando o ideal estético não é alcançado ${ }^{15}$.

As pessoas buscam viver, segundo Camon (1999), imerso emuma felicidade imediata, procuram prazeres e emoções, onde o protótipo perfeito exigidos pela comunidade e a mídia é algo inacessível e que ocasiona decepção ${ }^{12}$. A assimilação da imagem corporal é um enigmático fato que abrange particularidades intelectuais, afetivos, coletivos e culturais. Segundo Campana e Tavares (2009) ${ }^{\text {II: }}$ "Cada um de nós tem um padrão postural”, ou seja, uma figura inconsciente de si formada pela postura do corpo. A discrepância entre a percepção subjetiva da imagem corporal e o desejo do tipo ideal de corpo pode interferir no sentimento de satisfação e desencadear o desejo por mudanças na aparência, interferindo diretamente na saúde psíquica e no bem estar geral ${ }^{23}$.

Alguns estudos apontaram que as mulheres possuem uma maior percepção $(67,6 \%)$ em ter uma medida corporal menor e os homens $(66,7 \%)$ em ter uma silhueta maior. Podemos concluir que a autopercepção da IC está interligado o gênero e ao índice de massa corporal ${ }^{30}$. 


\subsection{Estigma social e preconceito}

"A obesidade" por si só, possui uma carga de preocupação e aflição, e como se não fosse o bastante, o quadro é piorado pela estigmatização social do corpo, onde o mesmo deve seguir padrões estéticos aceitáveis, imposto e julgado sempre pelo olhar do outro e da sociedade, onde o padrão corporal adequado e aceitável é o magro, então o indivíduo fora desse padrão se sente excluído e rejeitado, por se fazer pensar que não se encaixa nesses padrões ${ }^{10}$. No entanto, entende -se por estigma social: "uma marca social ou física, capaz de categorizar negativamente aquele que a detém, desvalorizando pessoas diferentes das que se encaixam nos padrões chamados de normais"10. $\mathrm{O}$ indivíduo estigmatizado atormenta-se por ter sua personalidade anulada, o que ocasiona grande consequências na vida dos indivíduos obesos, onde na maioria das vezes os mesmos buscam métodos para lidarem ou fugirem da problemática questão ${ }^{10}$. Desde muito cedo os indivíduos obesos são afetados com a discriminação, que podemos conceituar a mesma como uma forma de excluir o indivíduo obeso ou de o fazer se sentir inferior ${ }^{10}$

Alguns estudos evidenciaram que indivíduos em sobrepeso ou obesidade sofrem rejeição e perseguição por estarem acimas do peso, especificamente pessoas do sexo feminino, e são julgados como indigna, preguiçosa e displicente ${ }^{13}$.

A cidadã que tem a sua medida corpórea aumentada sofre uma repressão de princípios, sentindo-se rejeitada, desajeitada e rotulada ${ }^{12}$.

Segundo Novaes (2006)13: Este mundo é feito para os magros, jovens, brancos, caucasiano e sem nenhum tipo de deficiência física. Quem não pertence a um desses grupos, com certeza ficará á margem sofrendo inúmeros preconceitos.

\subsection{Pressão midiática, padronização corporal e consumismo desenfreado}

A opressão cultural para emagrecer é um componente relevante a ser estudado já que o mesmo está interligado aos transtornos alimentares, fatores biológicos, psicológicos e familiares ${ }^{27}$.

A comunidade exige demais perfeição estética e isso nos reprime.$^{17}$ É perceptível que a imprensa brasileira desempenha uma extensa interferência nesses jovens no que se refere ao objetivo de atingir a condição física perfeita. ${ }^{8} \mathrm{O}$ aprimoramento corporal pode ser visto 
como sinônimos de autoridade e ações capazes de intensificar o modo de ver e enxergar o mundo 25 .

Referente ao emagrecimento estético do corpo, constata-se uma uniformização da vontade e da concepção de corpo perfeito, ou seja, predomina um biótipo peculiar: corpo franzino, afilado, com formas delineadas e perfeitas, bem como é preconizado pela mídia ${ }^{12}$. Diversos meios de comunicação têm instigado e estabelecidos alguns padrões de corpos perfeitos e estilo de vida que na maioria das vezes só incentivam o consumismo descabível e o crescimento desenfreado do capitalismo. ${ }^{8}$

O capitalismo da atualidade utiliza o corpo como um mostruário para o universo, mostrando-se como o indivíduo deve ser, desse modo mostra uma separação entre o ser e o aparentar ser..$^{10}$

Os indivíduos decaem em decisões e na segurança vivendo sentimentos de ansiedade e incômodo, que induz a procura por coisas disponibilizadas pelo comércio ${ }^{14}$. Estudos anteriores evidenciaram que dentre os bens de consumo mais idealizados da atualidade é a estrutura física, e que a mesma se evidencia mais que aparelhos eletrônicos, automóveis, entre outros ${ }^{19}$.

É perceptível, então, que o consumismo induz as pessoas a uma fase de dependência, onde suas vontades são inacabáveis, em um rito de prazer a qualquer preço ${ }^{8}$. A beleza física e a consumação fazem parte do processo social na qual o consumo é o método do imaginativo, na qual os indivíduos possuem uma aparência agradável e peculiar ${ }^{26}$.

\subsection{Transtornos alimentares e Sofrimento Psíquico}

Os transtornos Alimentares( TA) são caracterizados como disfunções psiquiátricas que ocasiona danos à saúde do indivíduo e tem sérias consequências sobre a vida do mesmo ${ }^{6} . \mathrm{Na}$ discussão da pesquisa e temática verificou -se que há um aumento de pessoas insatisfeita com sua imagem corporal e a faixa etária mais atingida é os adolescentes e os jovens adultos, onde a grande maioria apresentam disfunções psicológicas sérias como bulimia, anorexia ,vigorexia, transtornos dismórfico corporal, depressão, entre outros distúrbios patológicos ${ }^{1}$. Os principais transtornos alimentares são: Anorexia nervosa (AN), Bulimia nervosa vigorexia e o transtorno dismórfico corporal ${ }^{6}$. A AN refere-se a perda de peso autoimposta 
por meio de dietas restritivas que buscam a magreza excessiva e a distorção da imagem do corpo $^{6}$. Já a bulimia podemos definir como afecção : "episódios repetidos de compulsão alimentar, acompanhados por comportamentos compensatórios inadequados, tais como vômitos auto-induzidos, mau uso de laxantes e diuréticos, jejuns ou exercícios físicos excessivos "19. A vigorexia ou síndrome de Adônis é um transtorno na qual a pessoa realiza práticas esportivas de forma intensa e contínua para ganhar massa muscular e definição corporal, sem se preocupar com eventuais consequências prejudiciais á saúde ${ }^{19}$. E o transtorno dismórfico (TDC), que é a preocupação excessiva com a imagem corporal, onde há uma preocupação com algum defeito irreal ou criado pelo imaginário de si $^{1}$. Segundo o programa de transtornos alimentares da USP (200I), o gênero feminino é atingido por o,5\% á ı\% que sofre de anorexia e ı\% á $2 \%$ de bulimia ${ }^{1}$.

A influência realizada pelas alegações dietéticas e pela mecanização do corpo na edificação da imagem corporal é excessiva e, nos últimos anos houve um aumento de pessoas que vem externando insatisfação com sua imagem corporal, evitando alguns alimentos e valendo-se de engrenagens que na maior parte são inadequadas para o processo de emagrecimento. ${ }^{7}$ Podemos definir alegações dietéticas como condutas e comportamentos alimentares inadequadas ao indivíduo, por exemplo, deixar de se alimentar, fazer jejuns sem nenhum suporte profissional, praticar atividades físicas extenuantes ${ }^{21}$. No Brasil, os estudos relativos com IC começaram no campo dos transtornos Alimentares(TA), na qual o objetivo a princípio era entender acontecimentos na existência alterada com sua estrutura corpórea e com sua IC. ${ }^{\text {II }}$

Alguns estudos evidenciaram que o gênero feminino é mais propenso a desenvolver insatisfação corporal, bulimia, obsessão com a magreza, baixa autoestima, insegurança interpessoal, perfeccionismo e ascetismo ${ }^{22} \cdot 62,8 \%$ dos homens apresentam insatisfação com a imagem corpórea e $67 \%$ das mulheres apresentam também insatisfação. ${ }^{24}$

A insatisfação com a magreza foi maior no gênero masculino de 2,71\% e a insatisfação com o aumento de peso foi 2,2\% maior no gênero feminino. ${ }^{24}$

Os padrões de beleza, vigorosamente instigados pelos meios digitais e consolidados pela comunidade, têm imposto especificidades Antropométricas cada vez mais distante da 
realidade, causando sofrimento sobre a imagem corpórea, mesmo estando com um estado nutricional apropriado para idade e gênero. ${ }^{7}$

Segundo Novaes (200I)12" impotentes para suportar as faltas, os sujeitos caem no desespero, na tristeza ou entregam-se às compulsões”. O paciente bariátrico após a cirurgia pode sofrer com a CA (compulsão alimentar) ou com o lance de abuso ou overdose, ocorrem geralmente em festividades sociais onde muitas das vezes há o incentivador a consumirem cada vez mais ${ }^{4}$. O termo " compulsão alimentar " é definido por qualquer comportamento onde o indivíduo se sente obrigado a comer e enxergado pelo o mesmo, como ausência de autodomínio 5 .

A magreza imposta pela sociedade e pelos meios de comunicação (televisão, Instagram, facebook, ,entre outros) tem ocasionado sofrimento psíquico sobre os indivíduos, onde predomina o sentimento de não pertença, de inexistência, angústia, desânimo e tristeza profunda ${ }^{10} 1^{4}$.

\subsection{Aumento de cirurgia Plástica e suas imprecisões}

A cirurgia plástica é uma intervenção cirúrgica que ocasiona mudanças na estrutura corporal, seja para fins "Aperfeiçoar algo" ou "consertar algo" e por ser um procedimento de intervenção no corpo o mesmo é considerado uma atividade de direito da personalidade. ${ }^{8} \mathrm{~A}$ cirurgia plástica é vista como um recurso milagroso, a de um sonho ${ }^{13}$. De acordo com a sociedade brasileira de cirurgia plástica e do Instituto Datafolha mostram um aumento na procura por cirurgias plásticas estéticas na faixa etária entre I4 e I8 anos. ${ }^{8}$

Segundo uma consulta conduzida pelo Datafolha em 2009, 73\% das cirurgias plásticas realizadas no Brasil foram feitas por estética. ${ }^{8}$ As categorias mais procuradas, respectivamente, foram aumento de mama, seguido por lipoaspiração e por fim cirurgias no abdômen. ${ }^{8}$ Além do mais, foram divulgados pela sociedade brasileira de cirurgia plástica que entre 2008 e 2012, sucedeu um acréscimo de $114 \%$ na execução de operações por jovens na faixa etária de 14 e i8 anos e que "o percentual de cirurgias plásticas" duplicou em quatro anos, pulou de 37.740 em 2008 para 91.100 em 2012, um aumento de I41\% a mais. ${ }^{8}$

Pessoas jovens são mais vulneráveis à interferência da mídia, em comparação com os mais velhos, de modo que a procura por procedimentos estéticos aumentam, persuadido na 
sua compreensão estética, em consequência, impactando no grau de contentamento. ${ }^{9}$ Supõem que as prováveis razões reveladas para a ascensão a fixação de procedimentos estéticos seja influenciada pela mídia, sem que ao menos os jovens tenham auto suficiência intelectual considerada, de forma que sua soberania se quer seja propriamente resguardada. ${ }^{8}$ Segundo a SBCP (2004) e JIFE (Junta internacional de fiscalização de entorpecentes (2007) apontam a estrutura corpórea como um aspecto de grande relevância no país, o que pode ser justificado pelas porcentagens de cirurgias plásticas estéticas e pela comercialização de fármaco para emagrecer ${ }^{27}$.

Os protótipos estéticos corporais são considerados como objetivos a serem atingidos, sem ao menos haver nenhuma meditação sobre a utilidade ou vantagens e sem que ao menos sejam colocadas em ênfase a sua singularidade e desejos. ${ }^{8}$ Além da disseminação dos padrões estéticos por parte da mídia, temos na atualidade, o crescimento do intitulado "Hedonismo pós moderno", onde há a busca incessante de tornar-se felizes a qualquer preço. ${ }^{8}$

Por último e não menos importante, o hedonismo pós moderno talvez seja uma das razões para o aumento expressivo da procura por cirurgias plásticas estéticas entre os jovens ${ }^{8}$. À medida com que as inovações tecnológicas e científicas se expandem mais espaço e visibilidade ganha a medicina estética, o que possivelmente justifique a demanda altíssima por cirurgias estéticas ${ }^{8}$.

A cirurgia bariátrica é um método considerável na diminuição do peso e na melhoria de doenças associadas à obesidade ${ }^{14}$. No entanto, estudos evidenciaram alguns efeitos negativos à saúde dos indivíduos, hábitos e condutas alimentares desajustadas, por exemplo, a compulsão alimentar, outro tipo de disfunção que atinge cerca de $3 \%$ dos brasileiros ${ }^{14} 1$. Além de apresentarem na sua maioria imprecisões, ou seja, complicações pós operatórias, por exemplo, infecções, hemorragias, dificuldade de cicatrização e além do mais, qualquer que seja a intervenção exige um espaço adequado, regulamentado pelos órgãos de fiscalização e profissionais qualificados para tal ação seguindo todos os protocolos de segurança exigido pela sociedade brasileira de cirurgias plásticas ${ }^{4}$. As imprecisões físicas são muito comum ocorrer no pós cirúrgico e se torna umas das causas que mais ocasiona transtorno psicológico, de uma a cada cirurgias plásticas de mama realizada, há a formação de hematomas nas mamas, infecções generalizadas, trombose, embolia pulmonar, e a cada 
15\% das mulheres que realizam esse procedimento, podem perder a sensibilidade dos mamilos. Ademais, a lipoaspiração pode ocasionar perfuração de algum órgão ou tecido, além surgir problemas com a anestesia geral, podendo desenvolver infecção em alguns órgãos como: pulmão, Abc e problemas cardíacos. Notoriamente, as complicações físicas, podem ocasionar as disfunções psicológicas, visto que há uma relação direta com a autopercepção de si e da autoestima do sujeito que se submete a tal procedimento 4 .

\section{CONSIDERAÇÕES FINAIS}

Diante dos achados acredita-se que seja primordial mantermos um olhar mais apurado e humanizado sobre essa temática e entendermos a periodicidade com que ocorre a insatisfação corporal na sociedade brasileira e quais consequências ou impactos a mesma acarreta sobre a saúde psíquica, emocional e nutricional dos indivíduos, afim de fomentar condutas e comportamentos alimentares e psicológicos saudáveis, além de minimizar a opressão psíquica ocasionada pela sociedade e pelas mídias digitais referente a opressão sobre a imagem corpórea, aspirando precaver os efeitos provocados pela contrariedade com a imagem corporal.

A vista disso faz-se necessário o trabalho multidisciplinar entre nutricionista e psicólogo, com intuito de unificar a psicoterapia e o planejamento dietético, a fim de buscar alternativas para alcançar seja qual for o objetivo (emagrecimento, hipertrofia ou manutenção de peso), sem que seja enxergado apenas a via cirúrgica e que coloquem em risco suas vidas. Durante A construção desse trabalho foi possível perceber que os sujeitos se submetem a estes procedimentos estéticos na buscar de atingir rapidamente seus objetivos estéticos, o que poderia ser alcançado com a orientação e planejamento dietoterápico a longo prazo. É notório que os jovens são mais suscetíveis a buscar esses procedimentos ou a desenvolverem hábitos e condutas alimentares inadequadas. Então a nutrição e a psicologia visam unir forças, no intuito de mostrar que nem todos os indivíduos precisam se submeter ao risco de intervenções, que é possível atingir o objetivo almejado cuidando do emocional ,psicológico, da alimentação e do físico. O Presente estudo tem relevância na área da nutrição, porque visa contribuir com a saúde pública da população, visando minimizar os impactos ocasionando pela insatisfação corporal e sua possíveis consequências sobre a saúde 
dos indivíduos como hábitos alimentares inadequados, jejuns sem orientação e acompanhamento do nutricionista, deficiências nutricionais, anemias, baixo peso, desenvolvimento de transtornos alimentares, depressão e ansiedade.

Além do mais faz necessário uma profunda reflexão sobre qual é o seu " padrão de beleza"?

Para uns pode ser apenas o externo, seguir a moda, para outros é ser de verdade, para outros é transcender o que de mais belo guardamos no nosso interior, tudo está relativamente interligado a nossa visão de mundo e consequentemente de nós mesmos. E por fim, enfatizo que padrão de beleza é ser de verdade, belo é enxergar as marcas e cicatrizes deixadas pelo tempo e aceita-las como um processo construtivo da sua história.

\section{REFERÊNCIAS}

I- Shilder (1994). De Aguiar G, D Agostini FP, DeMarco TT, Schlosser A. Transtorno alimentares (anorexia e bulimia) X padrão de beleza o que você vê quando se olha no espelho? V ciclos de debates em psocologia da unoesc campos videira. APEvda [Internet]. I8을 de dezembro de 2018 [citado 160 de abril de 2021]; 4: e2.0045.

https://portalperiodicos.unoesc.edu.br/apeuv/article/view/20045

2- Lima GF, Santos TV, Borges YS, Santos EP, Silva TM, Ramos CD. Ditadura da beleza. Revista Scienta Plena Jovem. 2017; 5, (I): I-5.

https://elibrary.tips/edoc/artigo-ditadura-da-beleza-dictatorship-of-beauty.html

3- Alves, (2011). Lima GF, Santos TV, Borges YS, Santos EP, Silva TM, Ramos CD, Ditadura da beleza. Revista Scienta Plena Jovem. 2017; 5, (I): I-5.

https://elibrary.tips/edoc/artigo-ditadura-da-beleza-dictatorship-of-beauty.html

4- Chaves JC, Figueira ML, Alves MB, Nunes MP. Disseminação dos padrões estéticos: A cirurgia plástica e a Hipervalorização da imagem. Revista eletrônica Materializando conhecimentos. Setembro de 2017; 8(-): I-I5.

https://www.redeicm.org.br/revista/indice-por-autor-2017/ 
5-Pinheiro T, Piovezan N, Batista H, Muner L. relação dos procedimentos estéticos com satisfação da autoimagem corporal e autoimagem corporal e autoestima de mulheres. Revista Cathedral [Internet]. IIfev.2020 [citado I6abr.202I]; 2(I). Available from: http://cathedral.ojs.galoa.com.br/index.php/cathedral/article/view/ro6

6-Shuwen QI, Ordoñez AM, Fernandes I. ocorrência de insatisfação corporal, comportamentos alimentares inadequados e pressão midiática em universitárias de diferentes áreas de estudo. [Monografia], Faculdade união das Américas,2019.

7-Silva LP, Tucan AR, Rodrigues EL, Del Ré PV, Sanches PM, Bresan D. insatisfação da imagem corporal e fatores associados: $u m$ estudo em jovens estudantes $\begin{array}{llll}\text { universitários.Einstein } & \text { (São } & \text { Paulo). } & \text { eAO17(4): }\end{array}$ http://dx.doi.org/ro.31744/einstein_journal/2019AO4642

8-Esser C, Penna I. O avanço da cirurgia plástica entre os adolescentes no Brasil: Uma discussão para a bioética [Dissertação]. Rio de Janeiro: Universidade Católica do Rio de Janeiro (PUC-RIO); 2оIо.

https://docplayer.com.br/4782218o-O-avanco-da-cirurgia-plastica-entre-os-adolescentesno-brasil-uma-discussao-para-a-bioetica.html

9- Torres Piski J. Hábitos deletérios fatores associados e Impactos psicossocial estético em jovens universitários: Resultados de um levantamento online[monografia]. Universidade Federal de juiz de Fora, campus Avançado de governador Valadares, Instituto de ciências da vida-ICV, 2019 .

http://repositorio.ufjf.br/jspui/bitstream/ufjf/ro463/I/joaofranciscotorrespiski.pdf

Io-Pinho LF. Ditadura da beleza: A cirurgia Bariátrica como método de alcance do padrão corporal estabelecido pela sociedade. Revista Brasileira de ciências da vida. 2017-07-II; v 5(3): I-22.

http://jornalold.faculdadecienciasdavida.com.br/index.php/RBCV/article/view/232 
II-Souza AC. Relações entre atividade física, corpo é imagem corporal entre universitários da Argentina, Brasil, Estados Unidos da América e França [Dissertação]. São Paulo: Faculdade de saúde Pública da Universidade de São Paulo; 2017.

https://www.teses.usp.br/teses/disponiveis/6/6138/tde-02082017-153802/pt-br.php

I2- o culto ao corpo na contemporaneidade [Internet]. www.webartigos.com. 2016 [cited 202I Nov 30]. Available from: https://www.webartigos.com/artigos/o-culto-ao-corpo-nacontemporaneidade/143545

13- Vilhena, Junia de, Joana, Rocha L. Comendo, comendo e não se satisfazendo: apenas uma questão cirúrgica? Obesidade mórbida e o culto ao corpo na sociedade contemporânea. Revista Mal Estar e Subjetividade [Internet]. 2021 [cited 2021 Nov 30];8(2):379-406. Available from: http://pepsic.bvsalud.org/scielo.php?script=sci_arttext\&pid=SI5I861482008000200006

I4- Monica Vanderlei Vianna Compulsão Alimentar \& Cirurgia Bariátrica: aspectos da fome que o bisturi não alcança Tese de Doutorado [Internet]. [cited 2021 Nov 30]. Available from: https://www.maxwell.vrac.puc-rio.br/35710/35710.PDF

15- Farah JFS, Castanho P. Dimensões psíquicas do emagrecimento: por uma compreensão psicanalítica da compulsão alimentar. Revista Latinoamericana de Psicopatologia Fundamental [Internet]. 2018 Jan [cited 202I Nov 30];21(I):4I-57. Available from: https://www.scielo.br/j/rlpf/a/ySZ5DqSd8cwZqcvSSmNcBQC/?lang=pt

ı6- Madeira MOM, Jorge MAC. O encantador do Isso - um retorno a Groddeck. Revista Latinoamericana de Psicopatologia Fundamental [Internet]. 2019 Jun [cited 2021 Nov 30];22(2):238-53. Available from: https://www.scielo.br/j/rlpf/a/LmxJX864634sXkjKJC6zc3k/?lang=pt

17- Laboratório de Psicopatologia Fundamental [Internet]. www.psicopatologiafundamental.org.br. [cited 202I Nov 30]. Available from: http://www.psicopatologiafundamental.org.br/uploads/files/ii_congresso_internacional/ mesas_redondas/ii_con._meu_corpo 
I8- Santos LN dos, Martins A. A originalidade da obra de Georg Groddeck e algumas de suas contribuições para o campo da saúde. Interface - Comunicação, Saúde, Educação [Internet]. $2013 \mathrm{Mar}$ [cited 2021 Nov 30];17(44):9-21. Available from: https://www.scielo.br/j/icse/a/yJ6cjwBgRqBXFSDTSQGp6zK/abstract/?lang=pt

I9- De Fátima M, Severiano V, Oliveira M. O corpo idealizado de consumo: paradoxos da hipermodernidade Érica Vila Real Montefusco Psicóloga (UFC) e Prof ${ }^{a}$ substituta do Depto. De Psicologia da UFC [Internet]. Revista Mal-estar e subjetividade -FoRtaleza. 2010 [cited 202I Nov 30] p. 137-65. Available from: http://pepsic.bvsalud.org/pdf/malestar/vionI/vioniao7.pdf

20- Joana, Junia Vilhena. Corpo corpo meu. Existe alguém mais imperfeito do que eu? [Internet]. ResearchGate. unknown; 2015 [cited 2021 Nov 30]. Available from: https://www.researchgate.net/publication/282862713_Corpo_corpo_meu_Existe_alguem_m ais_imperfeito_do_que_eu

21- Nicolino A da S. Primazia da beleza feminina e juventude empobrecida: notas de uma relação conflituosa. Interface - Comunicação, Saúde, Educação [Internet]. 2012 Apr 12 [cited 2021 Nov 30];16(40):83-94. Available from: https://www.scielo.br/j/icse/a/BzQ5JwKft3Qy7QZQS9qjhfj/?lang=pt

22- N. Hernández, R. Berengüí. Identidad deportiva y Trastornos de la Conducta Alimentaria: Estudio preliminar en deportistas de competición. Cuadernos de psicología del deporte [Internet]. 2016 [cited 202I Nov 30];16(2):37-44. Available from: https://dialnet.unirioja.es/servlet/articulo?codigo $=5634492$

23- Lôbo ILB, Mello MT de, Oliveira JRV de, Cruz MP, Guerreiro R de C, Silva A. Body image perception and satisfaction in university students. Revista Brasileira de Cineantropometria \& Desempenho Humano [Internet]. 2020 [cited 2021 Nov 30];22. Available https://www.scielo.br/j/rbcdh/a/ryfBLGfwZxczf 7 sfD9cK, $9 \mathrm{Gm} /$ ?lang=en

from:

24- Silva TR da, Saenger G, Pereira ÉF. Fatores associados à imagem corporal em estudantes de Educação Física. Motriz: Revista de Educação Física [Internet]. 20Ir Dec [cited 2021 Nov 30];17(4):630-9. Available from: https://www.scielo.br/j/motriz/a/cXMRWbQrPCDSr $3 \mathrm{CVqS}_{5} \operatorname{Rggr} /$ ?lang=pt 
25- Teixeira FLS, Freitas CMSMD, Caminha IDO. A beleza feminina como poder: desvendando outros sentidos para a construção estética de si. Revista Brasileira de Ciências do Esporte [Internet]. 2014 Apr [cited 202I Nov 30];36(2):485-500. Available from: https://www.scielo.br/j/rbce/a/jYRJ4qP4kFLKfjHdVfmDYSr/?lang=pt

26- MIZRAHI M. Cabelos ambíguos beleza, poder de compra e "raça" no Brasil urbano. Revista Brasileira de Ciências Sociais [Internet]. 2015 Jun II [cited 2021 Nov 30];30(89):31. Available from: https://www.scielo.br/j/rbcsoc/a/rMn8wWprFYmSCjgLYPBvR 4 P/?format=pdf\&lang= pt

27- Hirata E, Pérez-Nebra AR, Pilati R. Desenvolvimento e validação de escalas brasileiras de percepção e internalização de normas corporais. Psicologia: Reflexão e Crítica [Internet]. 2012 [cited 202I Nov 30];25(I):48-59. Available from: https://www.scielo.br/j/prc/a/nZXQSwzC33ZgJ5Q5yRRzcTR/?lang=pt

28- Witt J da SGZ, Schneider AP. Nutrição Estética: valorização do corpo e da beleza através do cuidado nutricional. Ciência \& Saúde Coletiva [Internet]. 20II Sep [cited 202I Nov 30];16(9):3909-I6. Available from: https://www.scielo.br/j/csc/a/5S9gmdRPLsRGhd7nyVqTRSf/?lang=pt

29-. Oliveira MR de, Machado JS de A. O insustentável peso da autoimagem: (re)apresentações na sociedade do espetáculo. Ciência \& Saúde Coletiva [Internet]. 202I Jul [cited 2021 Nov 30];26(7):2663-72. Available from: https://www.scielo.br/j/csc/a/JJ44yNWrLnvgVKknD3RPQkk/?lang=pt

30- Cassiano R, Rech, Denise Da E, Araújo S, Do J, Vanat R. [cited 2021 Nov 30]. Available from:

https://www.scielo.br/j/rbefe/a/Kb8sN8LtPyKhptnM938SQJk/?format=pdf\&lang=pt 